\title{
Role of N-acetylcysteine and GSH redox system on total and active MMP-2 in intestinal myofibroblasts of Crohn's disease patients
}

\author{
Cecilia Romagnoli • Tommaso Marcucci • \\ Lucia Picariello • Francesco Tonelli • \\ Maria Teresa Vincenzini • Teresa Iantomasi
}

Accepted: 11 December 2012 /Published online: 28 December 2012

(C) The Author(s) 2012. This article is published with open access at Springerlink.com

\begin{abstract}
Purpose Intestinal subepithelial myofibroblasts (ISEMFs) ${ }^{1}$ are the predominant source of matrix metalloproteinase-2 (MMP-2) in gut, and a decrease in glutathione/oxidized glutathione (GSH/GSSG) ratio, intracellular redox state index, occurs in the ISEMFs of patients with Crohn's disease (CD). The aim of this study is to demonstrate a relationship between MMP-2 secretion and activation and changes of GSH/GSSG ratio in ISEMFs stimulated or not with tumor necrosis factor alpha (TNF $\alpha)$.

Methods ISEMFs were isolated from ill and healthy colon mucosa of patients with active CD. Buthionine sulfoximine, GSH synthesis inhibitor, and N-acetylcysteine (NAC), precursor of GSH synthesis, were used to modulate GSH/ GSSG ratio. GSH and GSSG were measured by HPLC and MMP-2 by ELISA Kit.

Results In cells, stimulated or not with TNF $\alpha$, a significant increase in MMP-2 secretion and activation, related to increased oxidative stress, due to low GSH/GSSG ratio, was detected. NAC treatment, increasing this ratio, reduced MMP-2 secretion and exhibited a direct effect on the secreted MMP-2 activity. In NAC-treated and TNF $\alpha$-stimulated ISEMFs of CD patients' MMP-2 activity were restored to physiological value. The involvement of c-Jun N-terminal
\end{abstract}

C. Romagnoli $\cdot$ M. T. Vincenzini $\cdot$ T. Iantomasi $(\triangle)$

Dipartimento di Scienze Biochimiche,

Università degli Studi di Firenze, viale Morgagni 50,

50134 Florence, Italy

e-mail: tiantomasi@unifi.it

T. Marcucci $\cdot$ L. Picariello $\cdot$ F. Tonelli

Dipartimento di Fisiopatologia Clinica,

Università degli Studi di Firenze, viale Morgagni 85,

50134 Florence, Italy kinase pathway on redox regulation of MMP-2 secretion has been demonstrated.

Conclusion For the first time, in CD patient ISEMFs, a redox regulation of MMP-2 secretion and activation related to GSH/GSSG ratio and inflammatory state have been demonstrated. This study suggests that compounds able to maintain GSH/GSSG ratio to physiological values can be useful to restore normal MMP-2 levels reducing in CD patient intestine the dysfunction of epithelial barrier.

Keywords Total and active MMP-2 . Crohn's disease $\cdot$ GSH/ GSSG ratio $\cdot \mathrm{N}$-acetylcysteine $\cdot$ Oxidative state

\section{Introduction}

Intestinal subepithelial myofibroblasts (ISEMFs) play an important role in different functions in the normal and pathological intestine being involved in tissue growth and repair, tumourigenesis, inflammation and fibrosis [1]. The intestinal location of ISEMFs, subjacent to the basement membrane juxtaposed to the basal surface of epithelial cells, is crucial for their involvement in the regulation of many functions of epithelial cells, including epithelial cell proliferation and differentiation, mucosal protection and wound healing [2]. ISEMFs contribute in the epithelium repair processes by synthesizing, in response to stimuli, growth factors, such as transforming growth factor, epidermal growth factor, proinflammatory cytokines, components of extracellular matrix (ECM) and enzymes responsible of ECM degradation [1, 3]. Matrix metalloproteinases (MMPs), a family of $\mathrm{Zn}^{2+}$-containing neutral proteinases, are secreted as inactive zymogens and are activated in the extracellular space in order to cleave their substrates. Given 
that these enzymes are involved in the turnover and degradation of ECM, they play an important role in the normal tissue remodelling and in the modulation of matrix function [4]. Nevertheless, it has been demonstrated that MMPs act on substrates different from ECM proteins, regulate many physiological functions, such cell proliferation, adhesion, migration, growth factor bioavailability, chemotaxis and signalling. The activity of MMPs is tightly controlled. In fact, their latent form is activated, owing to the break of the interaction between the residue cysteine and the zinc ion present in the catalytic site. MMPs are also regulated at transcriptional level by interleukins, growth factors and proinflammatory mediators, such as tumour necrosis factor alpha (TNF $\alpha)$ [5]. Activated MMPs are inhibited by tissue inhibitors of metalloproteinases (TIMPs) which, by interacting with the catalytic site of MMPs, prevent their binding to substrates $[5,6]$. MMPs play a crucial role also in pathological conditions such as atherosclerotic lesion development, inflammation, arthritis, tumour progression and diabetes $[6,7]$. In an inflammatory state, such as in inflammatory bowel diseases (IBD), MMPs play the important role in controlling the function and migration of immune cells, chemokine activity, matrix deposition and degradation [8]. Nevertheless, a dysregulated expression of MMPs may contribute to intestinal tissue injury and inflammatory status in IBD [9], characterized by an imbalance between pro- and anti-inflammatory cytokines [10] and between synthesis and degradation of ECM components [11]. In fact, increased levels of MMPs found in inflamed tissue of IBD can be responsible of the ulceration and fistula formation [11]; on the contrary, an increased level of TIMP-1 protein is related to fibrotic structures restore [12]. In particular, in Crohn's disease (CD), an increase in MMP production occurs, which induces mucosal degradation, local leukocyte accumulation into inflamed tissue and cytokineproduction [11].

MMP-9 and MMP-2 are the two known gelatinases that degrade collagen; MMP-9 is produced principally by macrophages and polymorphonuclear leukocytes, differently from MMP-2 produced mainly by fibroblasts and other connective tissue cells [13]. Both are up-regulated in inflamed intestine of IBD patients, and their increase is associated with disease severity and activity [13, 14]. In particular, high levels of MMP-2 may contribute to epithelial barrier alteration that has a pivotal role in the pathogenesis of IBD (9).

ISEMFs are an important source of MMP-2; however, there are few known regulation mechanisms of the production and activity of this enzyme in ISEMFs of CD patients. Previously, we have demonstrated in intestinal mucosa and ISEMFs isolated from ill and healthy colonic mucosa of $\mathrm{CD}$ patients the presence of an increased oxidative state that was more remarkable in ill mucosa and in ISEMFs isolated from ill colonic mucosa of CD patients as compared to ISEMFs isolated from healthy mucosa $[15,16]$. It has been demonstrated that the effect of oxidative stress on the MMP-2 expression, and activity is cell-type dependent and tissue specific [17]. Considering these previous data, the aim of this study was to demonstrate a relationship between MMP-2 activity and secretion and change in the glutathione/oxidized glutathione ratio $(\mathrm{GSH} /$ GSSG ratio), in CD patient ISEMFs stimulated or not with $\mathrm{TNF} \alpha$. Indeed, TNF $\alpha$ is a largely produced cytokine in CD patients [18], and it is involved on MMP-2 regulation in serum and intestine of these patients [19]. For this purpose, we have determined total and active MMP-2 in ISEMFs, isolated from mucosa of CD patients and control group, in which the intracellular redox state was modulated through buthionine sulfoximine (BSO) or N-acetylcysteine (NAC), inhibitor and precursor of glutathione (GSH) synthesis, respectively. The results were also confirmed in CCD-18Co cells (18Co), a myofibroblast cell line derived from human colonic mucosa exhibiting many proprieties of ISEMFs [20].

\section{Materials and methods}

\section{Patients}

Surgical specimens were taken from macroscopically and microscopically inflamed and unaffected colonic mucosa of four patients affected by active CD (mean age, 33 years; range, 20-55). The diagnosis of $\mathrm{CD}$ was ascertained according to the usual clinical criteria [21], and the site and extent of the disease were confirmed by endoscopic, histology and enteroclysis. The primary site involved was ileocolonic in all patients which were also in active phase of disease as documented by the Crohn's disease activity index (ranging from 220-400). Patients with a score below 150 are considered to be in clinical remission, and scores above 450 reflect severe CD [20]. Moreover, the patients were treated with drugs prevalently used in CD pathology as mesalazine and steroids, but none of them had been treated with anti-TNF $\alpha$ therapies. Mucosal samples were also collected from colonic areas of four patients undergoing colectomy for colon cancer (mean age, 46 years; range, 36-60) used as control group. Steroid treatment was suspended at least 1 month earlier of surgery. All patients who participated in this study were recruited after their informed consent.

Cell cultures, treatments and stimulations

Primary cultures of ISEMFs were isolated from healthy and ill colonic mucosa of CD patients (HCD-ISEMFs and ICDISEMFs, respectively) and from mucosa of control group (CISEMFs) according the methods previously described by Mahida [22] and were grown to at least passage 4 before they were used in stimulation experiments. ISEMFs were 
characterized by immunocytochemical staining, as previously described [23]. 18Co cells (normal human colon myofibroblasts) were obtained from American Type Culture Collection (Manassas, VA, USA) and were used in our experiments with population doubling level (PDL) 24-36 given that the line begins to senesce at about $\mathrm{PDL}=42$. All cells were cultured at $37^{\circ} \mathrm{C}$ in a $5 \% \mathrm{CO}_{2}$ atmosphere in minimum essential medium with $2 \mathrm{mM}$ glutamine and $1.5 \mathrm{~g} / 1$ sodium bicarbonate, $0.1 \mathrm{mM}$ non-essential amino acids, $1 \mathrm{mM}$ sodium pyruvate and $10 \%$ foetal bovine serum. Culture media were supplemented with $72 \mathrm{mg} / \mathrm{l}$ penicillin and $100 \mathrm{mg} / \mathrm{ml}$ streptomycin.

ISEMFs were seeded in 12-well plates, serum starved at confluence for $48 \mathrm{~h}$ and subsequently stimulated for $24 \mathrm{~h}$ with $1 \mathrm{ng} / \mathrm{ml} \mathrm{TNF} \alpha$ (Sigma), at the same concentration previously used to stimulate these cells [16]. Forty eight-hour-starved CISEMFs were also stimulated after $25 \mu \mathrm{M}$ BSO treatment performed during the last $16 \mathrm{~h}$ of starvation. Other stimulation experiments were performed in all human ISEMF starved for $48 \mathrm{~h}$ in the presence or not of $20 \mathrm{mM}$ NAC added during the last $24 \mathrm{~h}$. Each experiment performed on one cell line was repeated in triplicate. Altogether, the colonic intestine cell lines used were 12: four obtained from intestine of four controls, eight from ill and healthy intestine of four CD patients.

$18 \mathrm{Co}$ cells, seeded in 12-well plates, were serum starved at confluence for $72 \mathrm{~h}$ and treated or not during the last $16 \mathrm{~h}$ or the last $24 \mathrm{~h}$ with $25 \mu \mathrm{M}$ BSO (named BSO) or $20 \mathrm{mM} \mathrm{NAC}$ (named NAC), respectively. Other studies were performed in 48-h-starved cells treated during the last $16 \mathrm{~h}$ with $25 \mu \mathrm{M}$ BSO and to which $20 \mathrm{mM}$ NAC was added for other $24 \mathrm{~h}$ after removal or not of $\mathrm{BSO}$; these cells were named NAC-BSO and $\mathrm{NAC}+\mathrm{BSO}$, respectively. Subsequently, after these all treatments, the cells were stimulated or not for other $24 \mathrm{~h}$ with $1 \mathrm{ng} /$ $\mathrm{ml} \mathrm{TNF} \alpha$. BSO, NAC and TNF $\alpha$ concentrations are those used previously to modulate intracellular redox state and which do not reduce viability according to trypan blue exclusion test [16].

Additional experiments were performed in serum-starved cells for $48 \mathrm{~h}$ in the presence or not of $25 \mu \mathrm{M}$ BSO for the last $16 \mathrm{~h}$ or $20 \mathrm{mM} \mathrm{NAC}$ for the last $24 \mathrm{~h}$ of starvation and subsequently treated for $24 \mathrm{~h}$ with inhibitors of mitogenactivated protein kinases (MAPKs) and in particular with $2 \mu \mathrm{M}$ SB203580 (p38 MAPK inhibitor) or $5 \mu \mathrm{M}$ UO126 (extracellular signal-regulated kinases (ERK1/2) inhibitor) or $10 \mu \mathrm{M}$ SP 600125 (c-Jun N-terminal kinase (JNK) (Calbiochem, La Jolla, CA, USA). These inhibitor concentrations used are those that induced the maximum inhibition without interfering with cellular viability.

\section{GSH/GSSG ratio assay}

GSH/GSSG ratio was obtained by cellular GSH and GSSG levels measured in confluent ISEMFs and $18 \mathrm{Co}$ seeded in 6well plates, treated as reported above and collected in $0.2 \mathrm{ml}$ of $5 \%(v / v)$ aqueous $\mathrm{HClO}_{4}$ plus $10 \mu \mathrm{l}$ of $1 \mathrm{mM} \gamma$-glutamyl- glutamate (internal standard). Cells were sonicated twice for $5 \mathrm{~s}$, and GSH and GSSG were measured in cell extracts by high-performance liquid chromatography (HPLC) methods as previously reported [24].

MMP-2 activity assay

For quantification of active and total (pro and active) MMP-2, the supernatants of ISEMFs and 18Co cells, the highsensitivity MMP-2 Activity Biotrak Assay System kit (GE Healthcare) was used according manufacturer's instructions. This assay is performed in microtitre wells precoated with anti-MMP-2 antibody that bound active MMP-2 able to activate a detection enzyme, which in turn activates a detectable chromogenic substrate. Total MMP-2 activity (endogenously active plus the proenzyme) is measured by the addition of $\alpha$ aminophenylmercuric acetate, which artificially activates the inactive form of MMP-2. Total and active MMP-2 levels were expressed in ISEMFs as fold increase over the total and active MMP-2 levels measured in untreated and unstimulated $\mathrm{C}$ ISEMFs. Total and active MMP-2 levels were expressed in $18 \mathrm{Co}$ as fold increase over the total and active MMP-2 levels measured in untreated and unstimulated $18 \mathrm{Co}$.

\section{SDS-PAGE zymography}

The effect of thiol compounds on the activity of secreted MMP-2 has been evaluated by gelatine zymography of untreated $18 \mathrm{Co}$ medium. Aliquots of MMP-2 containing medium of untreated and unstimulated $18 \mathrm{Co}$ cells underwent electrophoresis on $8 \%$ polyacrilamide gels containing gelatine $(1 \mathrm{mg} / \mathrm{ml})$. Samples were mixed $(10: 1 \mathrm{v} / \mathrm{v})$ with a sample buffer consisting of $50 \mathrm{mM}$ Tris-HCl pH6.8, $2 \%$ SDS, $20 \%$ glycerol and $0.03 \%$ bromophenol blue. After electrophoresis, the gels were then soaked in $2.5 \%$ Triton $\mathrm{X}-100$ (Sigma) on a shaker for $1 \mathrm{~h}$ at room temperature, then cut in strips and incubated overnight at $37^{\circ} \mathrm{C}$ in the activation buffer (50 mM Tris- $\mathrm{HCl} \mathrm{pH} 7.5,5 \mathrm{mM} \mathrm{CaCl}_{2}, 200 \mathrm{Mm}$ $\mathrm{NaCl}$ ) at room temperature containing $20 \mathrm{mM} \mathrm{NAC}$ or $25 \mu \mathrm{M}$ BSO. At the end of the incubation, the gels were stained with Coomassie brilliant blue R-250 (Sigma Aldrich, Italy) and distained with $30 \%$ methanol and $10 \%$ acetic acid. The gels were scanned by Chemo-Doc (Bio-Rad), utilizing the Quantity One program (Bio-Rad).

\section{Western blotting}

Analysis of phosphorylation of JNK was performed in ISEMFs and $18 \mathrm{Co}$ cells treated or not with BSO or NAC. Cells were lysed in ice-cold lysate buffer $(50 \mathrm{mM}$ Tris $/ \mathrm{HCl} \mathrm{pH}$ 7.5, $1 \%$ Triton X100, $150 \mathrm{mM} \mathrm{NaCl}, 100 \mathrm{mM} \mathrm{NaF}, 2 \mathrm{mM}$ EGTA, phosphatase and protease inhibitor cocktail, Sigma) and, after $15 \mathrm{~min}$ on ice, were centrifuged at $11,600 \times \mathrm{g}$ for 
$10 \mathrm{~min}$. Protein concentrations were determined by the bicinchoninic acid solution protein reagent assay (Pierce) [25] using bovine serum albumine as standard (Sigma). Equal amounts of total proteins (20-25 mg) were loaded in each line and were subjected to SDS/PAGE on $10 \%(w / v)$ gel and electrotransferred to PVDF membrane (GE Healtcare) that was probed with specific antibody anti-JNK (cell signalling). Subsequently, membranes were stripped by incubation for $30 \mathrm{~min}$ at $50{ }^{\circ} \mathrm{C}$ in buffer containing $62.5 \mathrm{mM}$ Tris/ $\mathrm{HCl}, \mathrm{pH}$ 6.7, $100 \mathrm{nM} 2$-mercaptoethanol, $2 \% \mathrm{SDS}$ and, after extensive washing, the membranes were reprobed with and anti-actin (cell signalling) to normalize and to perform a densitometric analysis. Secondary antibodies conjugated to horseradish peroxidase were used to detect antigen-antibody complexes with a chemiluminescence reagent kit (GE Healthcare). ChemidocQuantity-One software (Biorad Laboratories) was used to perform quantitative analyses, and values of the bands were expressed as percentage variations relative to values of unstimulated and untreated cells.

\section{Statistical analysis}

All experiments were carried out three or more times. Data are expressed as the mean \pm SEM, and statistical significance of the differences was determined using Student's $t$ test. $P \leq$ 0.05 was considered statistically significant.

\section{Ethical consideration}

All patients who have participated in this study had to have undergone an operation, and they were recruited after their informed consent. We have required only this because the surgeon should have anyhow resected the surgical samples that we have used for our experiments.

\section{Results}

MMP-2 secretion and activation in ISEMFs

Figure 1a shows the data obtained by the analysis of MMP-2 secretion (total) and activation in the culture medium of ISEMFs stimulated or not for $24 \mathrm{~h}$ with $1 \mathrm{ng} / \mathrm{ml} \mathrm{TNF} \alpha$. A significant enhanced secretion and activation of MMP-2 were measured in untreated and not TNF $\alpha$ stimulated CD-ISEMFs as compared to C-ISEMFs in the same conditions. Subsequently, TNF $\alpha$ stimulation induced a significant increase in both MMP-2 production and activity in all the untreated cells, and this effect was higher in CD-ISEMFs (Fig. 1a). Moreover, the greatest increase was measured in ICD-ISEMFs stimulated or not with TNF $\alpha$ in comparison with HCD-ISEMFs.

To identify a relationship between the variations obtained in MMP-2 secretion and activity and the different oxidative
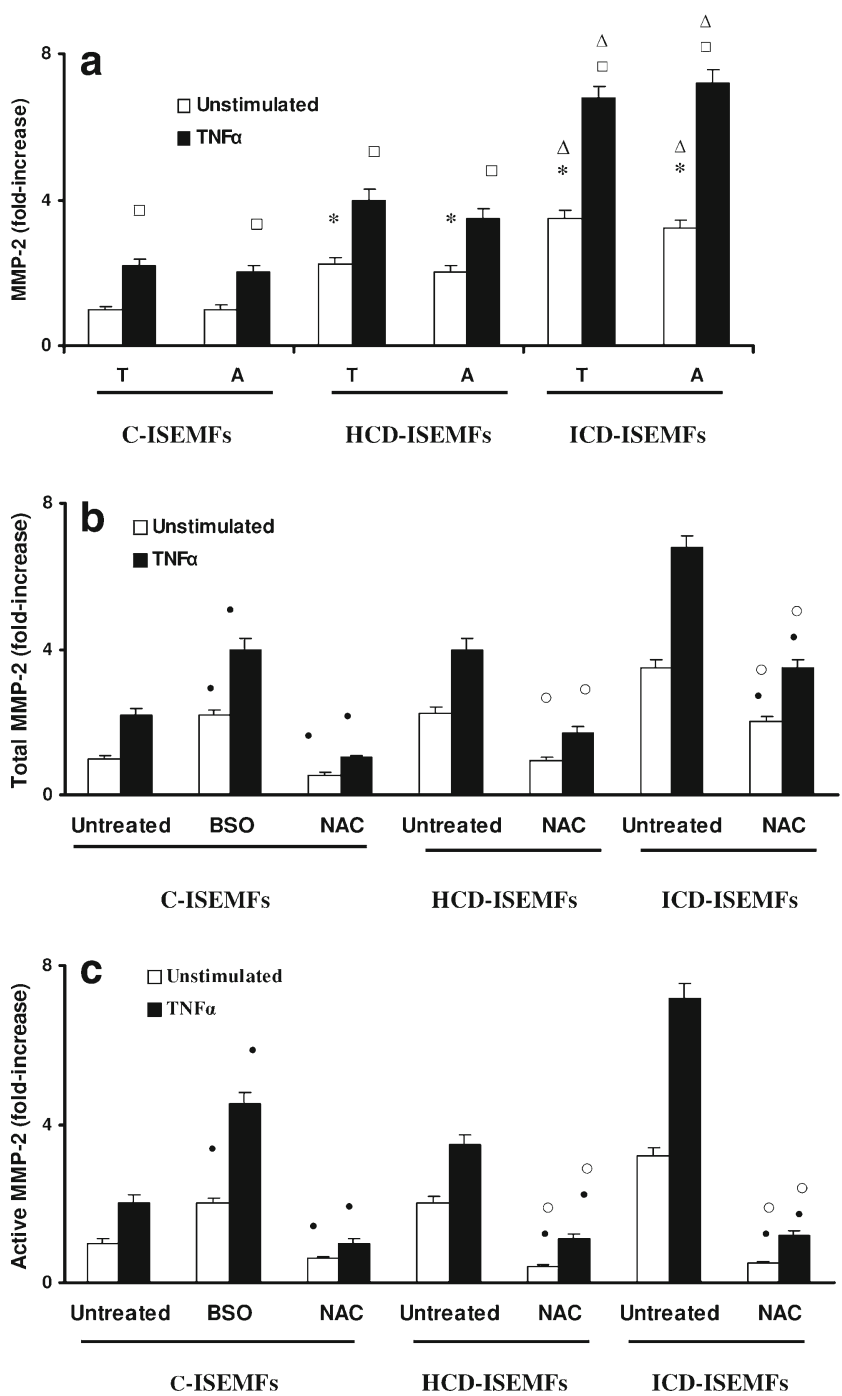

Fig. 1 Total and active MMP-2 levels in ISEMFs treated or not with $\mathrm{BSO}$ or NAC and stimulated or not with TNF $\alpha$. Starved cells treated or not with $25 \mu \mathrm{M}$ BSO or $20 \mathrm{mM}$ NAC, as reported in "Materials and methods," were stimulated or not for $24 \mathrm{~h}$ with $1 \mathrm{ng} / \mathrm{ml} \mathrm{TNF} \alpha$. The culture medium was collected and used to measure total and active MMP-2 by immunoenzymatic method. a Total (T) and active (a) MMP-2 in untreated and stimulated or not ISEMFs; b total MMP-2 in treated and stimulated or not ISEMFs; $\mathbf{c}$ active MMP-2 in treated and stimulated or not ISEMFs. The data, expressed as fold increase over the total and active MMP-2 values measured in untreated and unstimulated C-ISEMFs, are the mean \pm SEM of four experiments performed on four controls and four CD patients. Each experiment, repeated in triplicate, was performed on a cell line obtained from one control intestine or from ill or healthy intestine of one patient affected by CD. Single asterisk $\left(^{*}\right) p \leq 0.05$ compared to the unstimulated CISEMFs. White-filled square $(\square) p \leq 0.05$ compared to the respective unstimulated ISEMFs. White-filled triangle $(\Delta) p \leq 0.05$ compared to the respective HCD-ISEMFs. Bullet $(\bullet) p \leq 0.05$ compared to the respective untreated C-ISEMFs. White-filled circle $(\circ) p \leq 0.05$ compared to the respective untreated CD-ISEMFs

status previously determined in ISEMFs [16], MMP-2 values were measured in ISEMFs, in which GSH levels and GSH/GSSG ratio were modulated by treatment with $25 \mu \mathrm{M}$ 
BSO or 20 mM NAC [20]. Table 1 shows that GSH/GSSG ratio decreased in BSO-treated C-ISEMFs, as compared to untreated cells, and this value was similar to that detected in CD-ISEMFs. On the contrary, NAC treatment increased GSH/GSSG ratio in all the ISEMF groups, in comparison with the respective untreated cells, and restored in HCDISEMFs, the ratio to the values measured in C-ISEMF, whereas this did not occur in ICD-ISEMFs (Table 1).

Figure $1 \mathrm{~b}$ shows a significant increase in total MMP-2, as compared to untreated cells, in BSO-treated C-ISEMFs, stimulated or not with TNF $\alpha$. On the contrary, NAC treatment significantly reduced MMP-2 secretion in all ISEMFs groups, stimulated or not with TNF $\alpha$, as compared to the respective untreated cells. In particular, in HCD-ISEMFs, stimulated or not with $\mathrm{TNF} \alpha, \mathrm{NAC}$ treatment restored the values of MMP-2 secretion to those detected in untreated CISEMFs; whereas in ICD-ISEMFs, the total MMP-2 remained always higher than that measured in the same condition in C-ISEMFs even if, in the presence of NAC, a significant decrease, as compared to the respective untreated cells, was registered. These data suggest a direct relationship between the increase of total MMP-2 and that of intracellular oxidative state. This is evident considering the changes of GSH/GSSG ratio obtained in the various experimental conditions (Table 1). Moreover, MMP-2 activity increased significantly in BSO-treated C-ISEMFs stimulated or not with $\mathrm{TNF} \alpha$, as compared with the respective untreated CISEMFs (Fig. 1c). NAC treatment decreased similarly MMP-2 activity in all the ISEMF groups stimulated or not with TNF $\alpha$, differently to that observed for MMP-2 secretion. The values of active MMP-2 in unstimulated and NAC-treated ISEMFs were lower than those measured in

Table 1 Effect of NAC and BSO on the intracellular GSH/GSSG ratio in ISEMFs

\begin{tabular}{llll}
\hline & \multicolumn{2}{l}{ GSH/GSSG ratio } & \\
\cline { 2 - 4 } & C-ISEMFs & HCD-ISEMFs & ICD-ISEMFs \\
\hline- & $9.00 \pm 0.75$ & $6.70 \pm 0.40^{\mathrm{a}}$ & $4.70 \pm 0.25^{\mathrm{a}, \mathrm{c}}$ \\
NAC & $23.4 \pm 1.75^{\mathrm{a}}$ & $13.0 \pm 1.00^{\mathrm{b}}$ & $7.00 \pm 0.35^{\mathrm{a}, \mathrm{b}}$ \\
BSO & $5.80 \pm 0.48^{\mathrm{a}}$ & - & - \\
\hline
\end{tabular}

Starved cells were treated with $25 \mu \mathrm{M}$ BSO and/or $20 \mathrm{mM}$ NAC as reported in "Materials and methods," and GSH/GSSG ratio was determined by GSH and GSSG values detected by HPLC method. The data expressed as $\mathrm{nmol} / \mathrm{mg}$ proteins are the mean \pm SEM of four experiments performed, each in triplicate, on four controls and four CD patients. Each experiment, repeated in triplicate, was performed on a cell line obtained from one control intestine or from ill or healthy intestine of one patient affected by CD

${ }^{\mathrm{a}} p \leq 0.05$ compared to the untreated C-ISEMFs

${ }^{\mathrm{b}} p \leq 0.05$ compared to the respective untreated cells

${ }^{\mathrm{c}} p \leq 0.05$ compared to HCD-ISEMFs untreated and unstimulated C-ISEMFs. On the contrary, in TNF $\alpha$ stimulated cells, MMP-2 activity was similar to that measured in unstimulated and untreated C-ISEMFs.

MMP-2 secretion and activation in 18 Co cells treated or not with BSO or NAC

To validate the findings obtained in ISEMFs, the relation between MMP-2 secretion and activation and GSH/GSSG ratio was investigated also in $18 \mathrm{Co}$ cells treated or not with BSO or NAC. As reported previously [12] in 18Co cells, BSO decreased and NAC increased GSH/GSSG ratio (Fig. 2). This ratio was restored to the value measured in untreated cells when NAC was added to cells pretreated with BSO (NAC+ BSO) or after the removal of BSO (NAC-BSO) (Fig. 2). Figure $3 \mathrm{a}$, b shows that in BSO-treated $18 \mathrm{Co}$ cells stimulated or not with $\mathrm{TNF} \alpha$, the total and active MMP-2 significantly increased as compared to the respective untreated cells. The total and active MMP-2 levels were significantly reduced in NAC-treated $18 \mathrm{Co}$ cells, as compared to the respective untreated cells (Fig. 3a, b). In NAC+BSO- and NAC-BSOtreated cells, stimulated or not with TNF $\alpha$, MMP-2 secretion was restored to the values measured in the respective untreated cells (Fig. 3a) according to GSH/GSSG ratio (Fig. 2). On the contrary, the activity of MMP-2 in NAC, NAC+BSO- and NAC-BSO-treated $18 \mathrm{Co}$ cells, stimulated or not with TNF $\alpha$, was similarly lower than that detected in the respective untreated cells (Fig. 2b) independently of GSH/GSSG ratio (Fig. 2). Moreover, the active MMP-2 values detected in NAC-treated and TNF $\alpha$-stimulated 18 Co cells were very similar to the values of unstimulated and untreated $18 \mathrm{Co}$ (Fig. 3b). In order to determine whether the effects of NAC and BSO were due to a direct interference with the activity of secreted MMP-2, gelatin zymography of aliquots of untreated $18 \mathrm{Co}$ cell medium was performed. The gelatinolytic activity



Fig. 2 Effect of NAC and BSO on the intracellular GSH/GSSG ratio in $18 \mathrm{Co}$ cells. Starved cells were treated or not with $25 \mu \mathrm{M} \mathrm{BSO}$ and/or $20 \mathrm{mM}$ NAC as reported in "Materials and methods." GSH/GSSG ratio values, obtained by GSH and GSSG levels measured by HPLC method, are the mean \pm SEM of six experiments repeated in triplicate. Single asterisk $\left(^{*}\right) p \leq 0.01$ compared to the untreated cells. Section symbol $(\S)$ $p \leq 0.05$ compared to BSO treated cells 

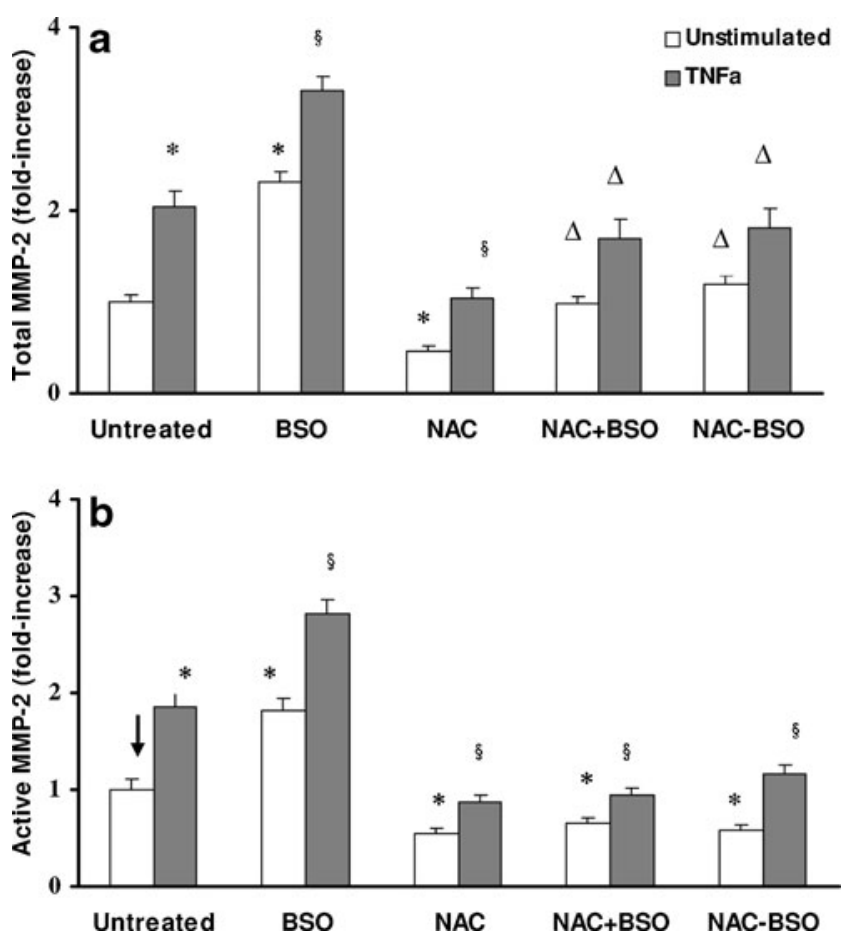

Fig. 3 Total and active MMP-2 levels in 18Co cells treated or not with BSO or NAC and stimulated or not with TNF $\alpha$. Starved cells treated or not with $25 \mu \mathrm{M}$ BSO and/or $20 \mathrm{mM} \mathrm{NAC}$, as reported in "Materials and methods," were stimulated or not for $24 \mathrm{~h}$ with $1 \mathrm{ng} / \mathrm{ml} \mathrm{TNF} \alpha$. The culture medium was collected and used for total (a) and active (b) MMP-2 assay by immunoenzymatic method. The data, expressed as fold increase of untreated and unstimulated cell values, indicated with the arrow, are the mean \pm SEM of six experiments repeated in triplicate. Single asterisk $\left(^{*}\right) p \leq 0.05$ compared to the untreated and unstimulated cells. White-filled triangle $(\Delta) p \leq 0.005$ compared to the respective BSO untreated and stimulated cells. Section symbol (§) $p \leq 0.05$ compared to the untreated and stimulated cells

was measured in gel cut in strips and incubated in the activation buffer containing $20 \mathrm{mM}$ NAC or $25 \mu \mathrm{M}$ BSO. Data, reported in Table 2, indicate that BSO was ineffective, while NAC reduced MMP- 2 activity of about $70 \%$.

Role of MAPK inhibitors on total MMP-2 in 18Co cells and ISEMF cells

Mitogen-activated protein kinases (MAPKs) are redoxregulated proteins [26] involved in the inflammatory response in colonic subepithelial myofibroblasts processes [27] and in the cascades participating in MMPs activation and expression [28-30]. Previously, we demonstrated that GSH depletion by BSO-activated ERK1/2 and p38MAPK increasing their phosphorylation in $18 \mathrm{Co}$ cells and in CISEMFs and that an increased activation of MAPKs occurred in HCD-ISEMFs and ICD-ISEMFs [16]. Therefore, we examined MMP-2 secretion in 18Co cells pre-incubated with specific inhibitors of MAPKs, U0126 for ERK1/2 [31],
Table 2 Effect of BSO and NAC on the activity of secreted MMP-2

\begin{tabular}{ll}
\hline Treatment & MMP-2 activity (\% of control) \\
\hline Control & $100 \pm 11.3$ \\
NAC $20 \mathrm{mM}$ & $30 \pm 7.9^{\mathrm{a}}$ \\
BSO $25 \mu \mathrm{M}$ & $108 \pm 14$ \\
\hline
\end{tabular}

Aliquots of MMP-2 containing medium of untreated 18 Co were run on polyacrilamide gels containing gelatine. Then, gels cut in strips were incubated in the activation buffer in the presence or not (control) of BSO or NAC as described in "Materials and methods." Values are the mean $\pm \mathrm{ESM}$ of three experiments

${ }^{\mathrm{a}} p \leq 0.01$ compared to control

SB203580 for p38 MAPK [32] and SP600125 for JNK [33]. Figure $4 \mathrm{a}$ shows that in untreated $18 \mathrm{Co}$ cells, only SP600125 significantly decreased the MMP-2 secretion; on the contrary, in BSO-treated cells, MMP-2 secretion was inhibited by the three MAPKs inhibitors even if JNK inhibitor induced the major decrease in total MMP-2. No inhibitor affected MMP-2 secretion in NAC-treated $18 \mathrm{Co}$ cells (Fig. 4a). Moreover, similar values were measured in untreated or BSO- or NAC-treated $18 \mathrm{Co}$ cells preincubated with SP600125 and were very similar among themselves (Fig. 4). Figure $4 \mathrm{~b}$ shows that, in the three groups of ISEMFs, MMP-2 secretion was significantly inhibited only by SP 600125 .

Effect of BSO or NAC on the phosphorylation of JNK in $18 \mathrm{Co}$ cells

To investigate the activation of JNK in conditions of the different oxidative state, JNK phosphorylation in all ISEMF group was detected. Figure 5a shows that the phosphorylation of JNK increased significantly in CD-ISEMFs, as compared to C-ISEMFs, and in ICD-ISEMFs, this phosphorylation was higher than that measured in HCD-ISEMFs. An activation of JNK phosphorylation in BSO-treated C-ISEMFs occurred with respect to untreated C-ISEMFs. On the contrary, JNK phosphorylation was reduced in all ISEMF groups treated with NAC as compared to the respective untreated ISEMFs. It is evident in Fig. 5a that NAC restored JNK phosphorylation to C-ISEMFs values only in HCD-ISEMFs in according to GSH/GSSG ratio. These results have been also confirmed in $18 \mathrm{Co}$ cells treated or not with BSO or NAC (Fig. 5b). The phosphorylation of JNK increased significantly in BSOtreated cells in comparison with the untreated ones and decreased in NAC-treated 18 Co cells. However, in NAC+BSOand in NAC-BSO-treated cells, the phosphorylation levels were restored to the values of untreated cells. Overall, these results agree with the behaviour of total MMP-2 levels (Fig. 1) and indicate that JNK phosphorylation is inversely related to GSH/GSSG ratio (Table 1, Fig. 2). 

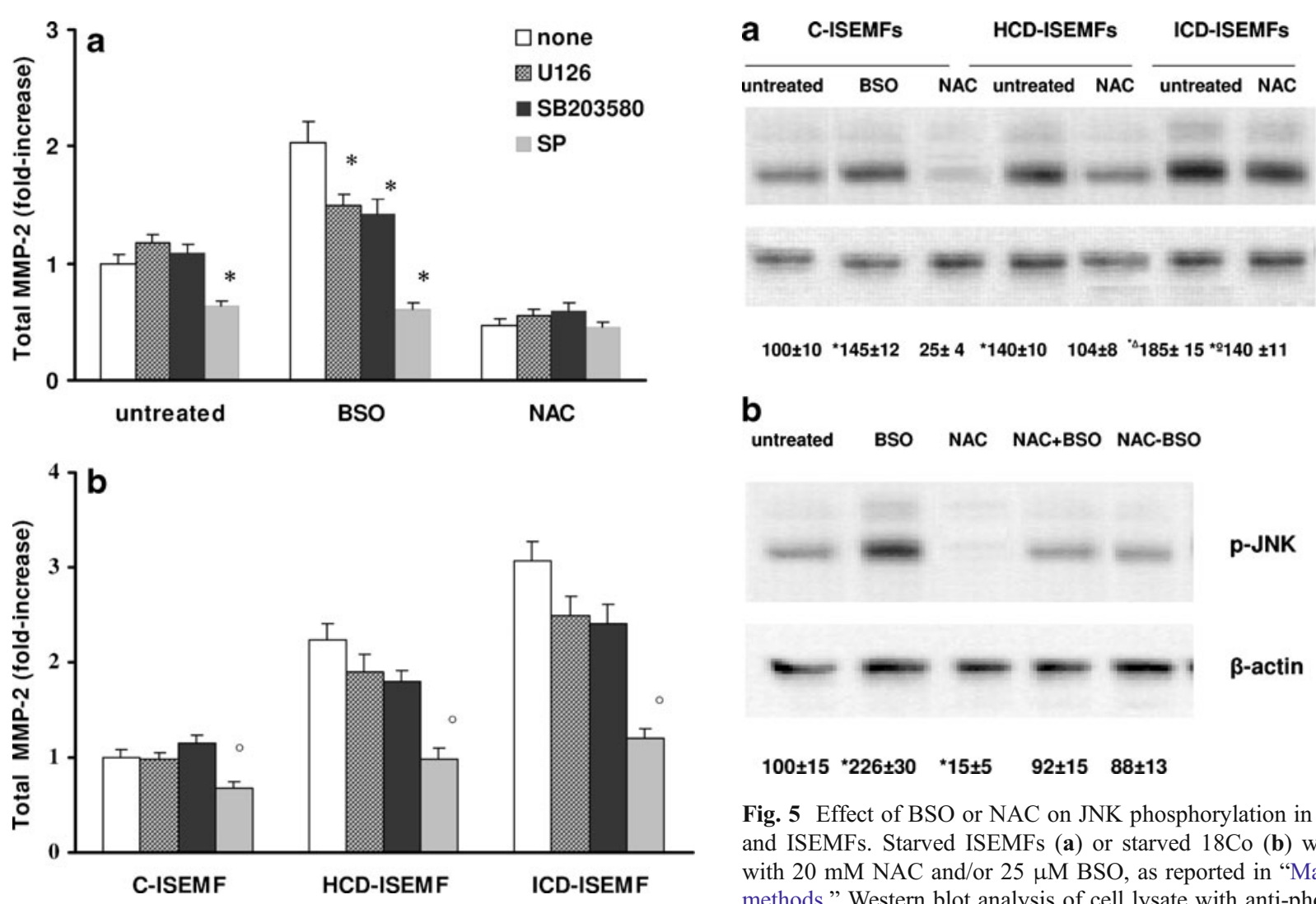

Fig. 4 Effect of inhibitors of MAPKs inhibitors on total MMP-2 levels in $18 \mathrm{Co}$ cells and ISEMFs; $2 \mu \mathrm{M}$ SB 203580 or $5 \mu \mathrm{M}$ U0126 or $10 \mu \mathrm{M}$ SP 600125 were added to starved $18 \mathrm{Co}$ cells, treated or not with 25 4M BSO or 20 mM NAC, as reported "Materials and methods," (a) and starved ISEMFs (b). Subsequently after $24 \mathrm{~h}$, the culture medium was collected and used for total MMP-2 assay by immunoenzymatic method. The data, expressed as fold increase of untreated cell values, indicated with the arrow, are the mean \pm SEM of six experiments repeated in triplicate for $18 \mathrm{Co}$ cells and the mean \pm SEM of four experiments performed on four controls and four CD patients. In ISEMFs, each experiment, repeated in triplicate, was performed on a cell line obtained from one control intestine or from ill or healthy intestine of one patient affected by CD. Single asterisk $\left(^{*}\right) p \leq 0.005$ compared to the respective $18 \mathrm{Co}$ cells without inhibitors. White-filled circle $(\circ) p \leq$ 0.05 compared to the respective ISEMFs without inhibitors

\section{Discussion}

Intestinal fibroblasts and ISEMFs are the predominant source of MMP-2 in gut [34-36], and an increase in the number of myofibroblasts in the intestine of $\mathrm{CD}$ patients occurs [37]. These cells, secreting ECM and MMPs, are involved in changes of tissue architecture in this pathology. MMP-2 is commonly expressed by normal tissue participating in the control of collagen homeostasis in tissue [38, 39], and MMP-2 staining in normal and inflamed colon is localized in subepithelial and fibroblast/myofibroblast besides in mononuclear macrophage-like cells [40]. Data reported in literature show that activation and expression of MMP-2 increase in inflamed colonic mucosa if compared with

Fig. 5 Effect of BSO or NAC on JNK phosphorylation in 18Co cells and ISEMFs. Starved ISEMFs (a) or starved 18Co (b) were treated with $20 \mathrm{mM}$ NAC and/or $25 \mu \mathrm{M} \mathrm{BSO}$, as reported in "Materials and methods." Western blot analysis of cell lysate with anti-phospho-JNK and anti- $\beta$-actin antibodies was performed. $p$-JNK values normalized with actin band were obtained by densitometric analysis of four separate experiments performed on four controls and four CD patients (a) or three separate experiments performed on $18 \mathrm{Co}$ cells (b). The values are reported as the mean percentage of phosphorylation \pm SEM relative to the values obtained in untreated C-ISEMFs or in untreated $18 \mathrm{Co}$ cells $(100 \%)$. Single asterisk $\left(^{*}\right) p \leq 0.05$ compared to the untreated CISEMFs (a) or untreated 18 Co cells (b). White-filled circle $(\circ) p \leq 0.05$ compared to the untreated ICD-ISEMFs. White-filled triangle $(\Delta) p \leq$ 0.05 compared to the untreated HCD-ISEMFs

non-inflamed colonic mucosa from the same CD patients $[13,14,41]$ leading to epithelial damage, intestinal ulceration and/or fistula formation [14, 42, 43]. In fact, the increase in MMP-2 is most pronounced in colonic mucosa ulceration of IBD patients and in fistulae of CD patients [14, 40]. In this study, we showed that a significant increase in total and active MMP-2 in CD-ISEMFs occurs, as compared to C-ISEMFs. Moreover, in ICD-ISEMFs, these increases are more remarkable than those measured in HCD-ISEMFs in accordance with the increase in oxidative stress that characterizes CD-ISEMFs and in particular ICD-ISEMFs [16]. Therefore, we demonstrated, for the first time in these cells, a relation between the up-regulation of MMP-2 secretion and activation, stimulated or not by $\mathrm{TNF} \alpha$, and the decrease in GSH/GSSG ratio measured in CD-ISEMFs. The strong relationship between this ratio and MMP-2 secretion was highlighted in ISEMFs and 18Co cells by modulating GSH/GSSG ratio through $\mathrm{NAC}$ and/or BSO treatment. Moreover, it has been demonstrated in $18 \mathrm{Co}$ cells 
that NAC is able to remove BSO effect, restoring GSH/ GSSG ratio and MMP-2 value to those of untreated cells. The dependence of the MMP-2 secretion from GSH/GSSG ratio is particularly evident in ISEMFs stimulated or not with TNF $\alpha$ and treated with NAC. In fact, in NAC-treated HCD-ISEMFs, the total MMP-2 levels and GSH/GSSG ratio are similar to those measured in untreated C-ISEMFs. On the contrary, in NAC-treated ICD-ISEMFs, MMP-2 secretion is lower than that of untreated C-ISEMF, in agreement with a higher value of GSH/GSSG ratio.

The increase in MMP-2 activity can be also related to GSH/ GSSG ratio decrease in CD-ISEMFs untreated and stimulated or not with $\mathrm{TNF} \alpha$, as compared to the respective untreated CISEMFs. This datum agrees with the activation induced by oxidants on $72 \mathrm{KDa}$ full-length MMP-2 through the disruption in the catalytic site of cysteine- $\mathrm{Zn}^{2+}$ interaction [4]. Other data show also an induction of pro-MMP-2 activity due to Sglutathiolation of the cysteine in the propeptide domain, related to an increase of oxidative state [44]. Effectively, in BSOtreated C-ISEMFs and 18Co cells, the decrease of GSH/ GSSG is related to the increase of MMP-2 activity.

Differently to what was observed for MMP-2 secretion, NAC effect on MMP-2 activity in ISEMFs and 18 Co cells is not related to the changes in GSH/GSSG ratio but to a direct effect of NAC on the proteinase, as demonstrated by gelatine zymography. In fact, NAC reduces MMP-2 activity in ISEMFs and 18Co equally and independently from GSH/ GSSG ratio. Moreover, NAC abolishes the stimulatory effect of TNF $\alpha$, restoring MMP-2 values in ISEMFs and $18 \mathrm{Co}$ cells to those of unstimulated and untreated C-ISEMFs and $18 \mathrm{Co}$, respectively. The increased production of TNF $\alpha$ occurs during inflammation in the colon, and this stimulates the MMP-2 secretion $[35,36]$. Our results suggest that TNF $\alpha$ in $\mathrm{CD}$ can amplify the inflammatory response also through the upregulation of MMP-2 secretion and activation in ISEMFs. In fact, an increased MMP-2 activity may play a role in the degradation of basement membrane which represents the support for endothelial and epithelial cells [40], increasing invasion of inflammatory cells [45]. Moreover, in ISEMFs, MMP2 could be involved in the development of fibrosis, such as it occurs in the hepatic fibrosis [46]. Therefore, for this, it should be very important to maintain MMP-2 values at physiological levels. Therefore, NAC, which reduces in ISEMFs MMP-2 secretion by the increase of GSH/GSSG ratio and suppresses the activation of MMP-2 induced by TNF $\alpha$, presents an important dual role in the normalization of MMP-2 values.

MAPK pathways can be activated by oxidative stress, and they play an important role in the regulation of MMP expression [47-49]. Our data show that JNK is principally involved in the secretion of MMP-2 both in ISEMFs and in $18 \mathrm{Co}$ cells, and JNK phosphorylation levels in both cell types are related to GSH/GSSG ratio. However, in BSOtreated $18 \mathrm{Co}$ cells, a low but significant reduction total
MMP-2 occurs also in the presence of ERK1/2 and p38 MAPK inhibitors showing a partial involvement of these kinases on total MMP-2 levels. In fact, previously, we also observed in BSO-treated 18Co cells an increase in ERK1/2 and p38 MAPK phosphorylation [16]. Differently to what verified for ERK1/2 and p38 MAPK [16], NAC decreases the JNK phosphorylation in 18Co cells and ISEMFs; this is in accordance with the increase in GSH/GSSG ratio and the decrease in total MMP-2. NAC restores in 18Co cells JNK phosphorylation to the levels of untreated cells after and during BSO treatment, as such as restores GSH/GSSG ratio and total MMP-2. Differently to that occurs in HCDISEMFs, NAC treatment in ICD-ISEMFs does not restore JNK phosphorylation, GSH/GSSG ratio and MMP-2 levels to values of C-ISEMFs confirming the relationship among them. All together, these data show that NAC downregulation effect on MMP-2 secretion is comparable to that observed with JNK inhibitor, suggesting that the increase of GSH/GSSG ratio induced by NAC reduces MMP-2 secretion inhibiting JNK. In fact, JNK can phosphorylate transcription factors such as JunB, JunD, c-fos, ATF2 and ATF3, which, along with c-Jun, make up the activator protein-1 transcription factor (AP-1) [50]. AP-1 modulates the expression of several stress-responsive genes and is an element found in most MMP promoters [51].

\section{Conclusions}

Our finding in CD-ISEMFs demonstrates (1) a relationship among MMP-2 secretion and activation, GSH/GSSG ratio and inflammatory state; (2) the involvement of ISEMFs, stimulated or not with TNF $\alpha$, in the increased activity and production of MMP-2 in intestinal mucosa of CD patients; (3) that NAC induced down-regulation of MMP-2 secretion through the increase of GSH/GSSG ratio, and this together with a direct action of NAC on the enzyme contribute to reduce MMP-2 activity; (4) that NAC may also suppress MMP-2 activation induced by TNF $\alpha$ and restore MMP-2 activity to physiological levels; and (5) the involvement of JNK pathway on redox regulation of MMP-2 secretion.

Moreover, this study suggests that compounds are able to modulate GSH components and to maintain GSH/GSSG ratio to physiological values can be useful to restore MMP-2 activity to normal values acting only on MMP-2 secretion and not directly on its activity. Indeed, the restore of normal MMP-2 level activity and/or expression can be important for help reduce in intestine of CD patients the dysfunction of epithelial barrier.

Acknowledgments This study was supported by a donation from the Ministero dell'Istruzione, dell'Università e della Ricerca and Fondazione Cassa di Risparmio di Firenze. 
Open Access This article is distributed under the terms of the Creative Commons Attribution License which permits any use, distribution, and reproduction in any medium, provided the original author(s) and the source are credited.

\section{References}

1. Andoh A, Bamba S, Brittan M et al (2007) Role of intestinal subepithelial myofibroblasts in inflammation and regenerative response in the gut. Pharmacol Ther 114:94-106

2. Andoh A, Bamba S, Fujiyama Y et al (2005) Colonic subepithelial myofibroblasts in mucosal inflammation and repair: contribution of bone marrow-derived stem cells to the gut regenerative response. J Gastroenterol 40:1089-1099

3. Powell DW, Adegboyega PA, Di Mari JF, Mifflin RC (2005) Epithelial cells and their neighbors I. Role of intestinal myofibroblasts in development, repair, and cancer. Am J Physiol Gastrointest Liver Physiol 289:G2-G7

4. Ra HJ (2007) Parks WC Control of matrix metalloproteinase catalytic activity. Matrix Biol 26:587-596

5. Spinale FG (2007) Myocardial matrix remodeling and the matrix metalloproteinases: influence on cardiac form and function. Physiol Rev 87:1285-1342

6. Lemaître V, D'Armiento J (2006) Matrix metalloproteinases in development and disease. Birth Defects Res C Embryo Today 78:1-10

7. Butler GS, Overall CM (2009) Updated biological roles for matrix metalloproteinases and new "intracellular" substrates revealed by degradomics. Biochemistry 48:10830-10845

8. Parks WC, Wilson CL, López-Boado YS (2004) Matrix metalloproteinases as modulators of inflammation and innate immunity. Nat Rev Immunol 4:617-629

9. Ravi A, Garg P, Sitaraman SV (2007) Matrix metalloproteinases in inflammatory bowel disease: boon or a bane? Inflamm Bowel Dis 13:97-107

10. Reimund JM, Wittersheim C, Dumont S et al (1996) Increased production of tumour necrosis factor-alpha interleukin-1 beta, and interleukin- 6 by morphologically normal intestinal biopsies from patients with Crohn's disease. Gut 39:684-689

11. Naito Y, Yoshikawa T (2005) Role of matrix metalloproteinases in inflammatory bowel disease. Mol Aspects Med 26:379-390

12. McKaig BC, McWilliams D, Watson SA, Mahida YR (2003) Expression and regulation of tissue inhibitor of metalloproteinase-1 and matrix metalloproteinases by intestinal myofibroblasts in inflammatory bowel disease. Am J Pathol 162:1355-1360

13. Gao Q, Meijer MJ, Kubben FJ et al (2005) Expression of matrix metalloproteinases-2 and -9 in intestinal tissue of patients with inflammatory bowel diseases. Dig Liver Dis 37:584-592

14. von Lampe B, Barthel B, Coupland SE et al (2000) Differential expression of matrix metalloproteinases and their tissue inhibitors in colon mucosa of patients with inflammatory bowel disease. Gut 47:63-73

15. Iantomasi T, Marraccini P, Favilli F et al (1994) Glutathione metabolism in Crohn's disease. Biochem Med Metab Biol 53:87-91

16. Catarzi S, Favilli F, Romagnoli C et al (2011) Oxidative state and IL-6 production in intestinal myofibroblasts of Crohn's disease patients. Inflamm Bowel Dis 17:1674-1684

17. Vincenti MP, Brinckerhoff CE (2007) Signal transduction and cell-type specific regulation of matrix metalloproteinase gene expression: can MMPs be good for you? J Cell Physiol 213:355-364

18. Papadakis KA, Targan SR (2000) Tumor necrosis factor: biology and therapeutic inhibitors. Gastroenterology 119:1148-1157
19. Gao Q, Meijer MJ, Schlüter UG, van Hogezand RA, van der Zon JM, van den Berg M, van Duijn W, Lamers CB, Verspaget HW (2007) Infliximab treatment influences the serological expression of matrix metalloproteinase (MMP)-2 and -9 in Crohn's disease. Inflamm Bowel Dis 13:693-702

20. Valentich JD, Popov V, Saada JI, Powell DW (1997) Phenotypic characterization of an intestinal subepithelial myofibroblast cell line. Am J Physiol 272:C1513-C1524

21. Best WR, Becktel JM, Singleton JW, Kern F Jr (1976) Development of a Crohn's disease activity index. National Cooperative Crohn's Disease Study. Gastroenterology 70:439-444

22. Mahida YR, Galvin AM, Gray T et al (1997) Migration of human intestinal lamina propria lymphocytes, macrophages and eosinophils following the loss of surface epithelial cells. Clin Exp Immunol 109:377-386

23. Di Sabatino A, Pender SL, Jackson CL et al (2007) Functional modulation of Crohn's disease myofibroblasts by anti-tumor necrosis factor antibodies. Gastroenterology 133:137-149

24. Iantomasi T, Favilli F, Degl'Innocenti D, Vincenzini MT (1999) Increased glutathione synthesis associated with platelet-derived growth factor stimulation of NIH3T3 fibroblasts. Biochim Biophys Acta 1452:303-312

25. Smith PK, Krohn RI, Hermanson GT et al (1985) Measurement of protein using bicinchoninic acid. Anal Biochem 150:76-85

26. Matsuzawa A, Ichijo H (2008) Redox control of cell fate by MAP kinase: physiological roles of ASK1-MAP kinase pathway in stress signaling. Biochim Biophys Acta 1780:1325-1336

27. Hata K, Andoh A, Shimada M et al (2002) IL-17 stimulates inflammatory responses via NF-kappaB and MAP kinase pathways in human colonic myofibroblasts. Am J Physiol Gastrointest Liver Physiol 282:G1035-G1044

28. Lin CW, Hou WC, Shen SC et al (2008) Quercetin inhibition of tumor invasion via suppressing PKC delta/ERK/AP-1-dependent matrix metalloproteinase-9 activation in breast carcinoma cells. Carcinogenesis 29(9):1807-1815

29. Cohen M, Meisser A, Haenggeli L, Bischof $P$ (2006) Involvement of MAPK pathway in TNF-alpha-induced MMP-9 expression in human trophoblastic cells. Mol Hum Reprod 12:225-232

30. Kajanne R, Miettinen P, Mehlem A et al (2007) EGF-R regulates MMP function in fibroblasts through MAPK and AP-1 pathways. J Cell Physiol 212:489-497

31. Hotokezaka H, Sakai E, Kanaoka K et al (2002) U0126 and PD98059, specific inhibitors of MEK, accelerate differentiation of RAW264.7 cells into osteoclast-like cells. J Biol Chem 277:47366-47372

32. Guo RX, Zhang M, Liu W et al (2009) NMDA receptors are involved in upstream of the spinal JNK activation in morphine antinociceptive tolerance. Neurosci Lett 467:95-99

33. Rossa C Jr, Liu M, Patil C, Kirkwood KL (2005) MKK3/6-p38 MAPK negatively regulates murine MMP-13 gene expression induced by IL-1beta and TNF-alpha in immortalized periodontal ligament fibroblasts. Matrix Biol 24:478-488

34. McKaig BC, McWilliams D, Watson SA, Mahida YR (2003) Expression and regulation of tissue inhibitor of metalloproteinase-1 and matrix metalloproteinases by intestinal myofibroblasts in inflammatory bowel disease. Am J Pathol 162:1355-1360

35. Monteleone G, Caruso R, Fina D et al (2006) Control of matrix metalloproteinase production in human intestinal fibroblasts by interleukin 21. Gut 55:1774-1780

36. Okuno T, Andoh A, Bamba S et al (2002) Interleukin-1beta and tumor necrosis factor-alpha induce chemokine and matrix metalloproteinase gene expression in human colonic subepithelial myofibroblasts. Scand J Gastroenterol 37:317-324

37. Theiss AL, Simmons JG, Jobin C, Lund PK (2005) Tumor necrosis factor (TNF) alpha increases collagen accumulation and proliferation in intestinal myofibroblasts via TNF receptor 2. J Biol Chem 280:36099-36109 
38. Matrisian LM (1994) Matrix metalloproteinase gene expression. Ann N Y Acad Sci 732:42-50

39. Agren MS (1994) Gelatinase activity during wound healing. Br J Dermatol 131:634-640

40. Kirkegaard T, Hansen A, Bruun E, Brynskov J (2004) Expression and localisation of matrix metalloproteinases and their natural inhibitors in fistulae of patients with Crohn's disease. Gut 53:701-709

41. Meijer MJ, Mieremet-Ooms MA, van der Zon AM et al (2007) Increased mucosal matrix metalloproteinase-1, $-2,-3$ and -9 activity in patients with inflammatory bowel disease and the relation with Crohn's disease phenotype. Dig Liver Dis 39: 733-739

42. Stallmach A, Chan CC, Ecker KW et al (2000) Comparable expression of matrix metalloproteinases 1 and 2 in pouchitis and ulcerative colitis. Gut 47:415-422

43. Matsuno K, Adachi Y, Yamamoto H et al (2003) The expression of matrix metalloproteinase matrilysin indicates the degree of inflammation in ulcerative colitis. J Gastroenterol 38: 348-354

44. Svineng G, Ravuri C, Rikardsen O et al (2008) The role of reactive oxygen species in integrin and matrix metalloproteinase expression and function. Connect Tissue Res 49:197-202
45. Ye H, Cai PC, Zhou Q, Ma WL (2011) Transforming growth factor$\beta 1$ suppresses the up-regulation of matrix metalloproteinase- 2 by lung fibroblasts in response to tumor necrosis factor- $\alpha$. Wound Repair Regen 19:392-399

46. Galli A, Svegliati-Baroni G, Ceni E et al (2005) Oxidative stress stimulates proliferation and invasiveness of hepatic stellate cells via a MMP2-mediated mechanism. Hepatology 5:1074-1084

47. Alge-Priglinger CS, Kreutzer T, Obholzer K et al (2009) Oxidative stress-mediated induction of MMP-1 and MMP-3 in human RPE cells. Invest Ophthalmol Vis Sci 50:5495-5503

48. McCubrey JA, Lahair MM, Franklin RA (2006) Reactive oxygen species-induced activation of the MAP kinase signaling pathways. Antioxid Redox Signal 8:1775-1789

49. Li L, Chen P, Ling Y et al (2011) Inhibitory effects of GL-V9 on the invasion of human breast carcinoma cells by downregulating the expression and activity of matrix metalloproteinase-2/9. Eur J Pharm Sci 43:393-399

50. Roy PK, Rashid F, Bragg J, Ibdah JA (2008) Role of the JNK signal transduction pathway in inflammatory bowel disease. World J Gastroenterol 14:200-202

51. Wu X, Li L (2012) Rosiglitazone suppresses lipopolysaccharideinduced matrix metalloproteinase- 2 activity in rat aortic endothelial cells via Ras-MEK1/2 signaling. Int J Cardiol 158:54-58 